www.jmscr.igmpublication.org

Impact Factor (SJIF): 6.379

Index Copernicus Value: 71.58

ISSN (e)-2347-176x ISSN (p) 2455-0450

crossref DOI: _https://dx.doi.org/10.18535/jmscr/v6i4.67

Journal Of Medical Science And Clinical Research

\title{
A Comparative Study of Results of Transfixation Screw and Loop Fixation for Coracoclavicular Stabilisation in Acromioclavicular Joint Dislocation
}

\author{
Authors \\ Dr Rahul Mandal ${ }^{1}$, Dr Atul Uttamrao Tat ${ }^{2}$ \\ ${ }^{1}$ RMO-CT (Tutor), Dept. of Orthopaedics, Medical College, Kolkata, ${ }^{2}$ Associate consultant, Revival Bone \& \\ Joint hospital \\ Corresponding Author \\ Dr Rahul Mandal \\ Email:rm6668@gmail.com
}

\begin{abstract}
Introduction: Transfixation screw and loop fixation with mersilene tape and endobutton both are well established surgical methods for management of acute AC joint injuries.

Materials and Methods: Patients meeting inclusion criteria between June,2013 to June,2015 were operated and followed up subsequently.

Result: Out of 26 patients 1 was lost to follow up and 1 excluded for not meeting inclusion criteria. Eventually, our sample size became 24 out of which Transfixation group and Loop fixation group compromised 12 patients each.

Conclusion: All of our patients reported satisfactory outcomes regardless the procedure adopted. Younger age group and non-meniscal injury group shows better outcome.

Keywords: Acute AC joint injuries, Transfixation screw, Loop fixation with mersilene tape and endobutton.
\end{abstract}

\section{Introduction}

The first studies on acromioclavicular (AC) injuries repair were by Hippocrates, Galen, and Paul of Aegina ${ }^{1}$. They recommended conservative management with compressive bandages to keep the clavicle in a normal position. Sir Samuel Cooper in 1861, used a loop of silver wire to approximate the clavicle and acromion process was credited for first time surgical intervention for AC joint injuries ${ }^{1}$. Mostly, the injury occurs when a direct force is applied to the upper part of the acromion, when, during the fall, the arm is in adduction. Less commonly, the injury occurs when a force is applied indirectly like, for instance, when a person falls on a stretched-out $\mathrm{arm}^{2,3}$. AC joint injuries mostly affect athletes, especially those who engage in contact sports (football, rugby, judo, hockey) ${ }^{4}$. Also, men are five to ten times more likely to be affected than women. These injuries are very common and cause up to $40 \%$ of all shoulder injuries and up to $3 \%$ of all sports injuries ${ }^{5}$. Rockwoodclassified AC joint injuries into six types ${ }^{6,7}$. In general, it is commonly accepted that lower degree AC joint injuries (I-III degree) are treated conservatively, while higher degree AC joint injuries (IV-VI degree) are treated surgically. There is, however, lack of consensus on the treatment of type III 
which was managed by both conservatively and operatively $^{8}$. There is a number of different surgical approaches to fix the AC joint, such as the use of Kirschner wires ${ }^{9}$, cerclage wires, transfixation screws ${ }^{10}$, different types of plates ${ }^{11}$, together with the use of sutures ${ }^{12}$, ligament transpositions ${ }^{13}$, or various transplants (fascia lata, hamstring tendons, etc. $)^{14,15}$. The newest techniques include arthroscopic fixations ${ }^{16,17}$, the use of which requires endobutton, anchor with or without tendon grafts. The goal of this study was to compare results of the surgical approaches to acute injuries of the AC joint by Transfixation screw (TS) technique and Loop fixation(LF)with mersilene tape $\&$ endobutton and their merits and demerits.

\section{Materials and Methods}

This study conducted in department of orthopaedics in R G Kar Medical College \& Hospital, Kolkata, West Bengal after taking written \& informed consent from patients \& ethical clearance. Twenty-six acute AC joint injuries were operated between June ,2013 and June,2015. The inclusion criteria were age more than 18 years and Rockwood Type III, IV, V, VI injuries. The exclusion criteria were ipsilateral fracture in humerus, scapula \& elbow, open injuries, Rockwood Type I, II injuries and associated neurovascular injury.One patient excluded as his age was 14years and another patient was lost during follow up. Therefore, 24 patients were available for evaluation. Every alternate case was treated by Transfixation screw and Loop fixation. Among 24 cases there were 11 type III, 7type IV, 4 type V and 1 type VI injuries.

\section{Pre-Operative Planning}

Clinically suspected cases of AC joint injury further examined by radiologically. Anteroposterior view and axillary lateral view and stress view are taken. Cases meeting both inclusion and exclusion criterion are evaluated further and DASH score and Constant score was.

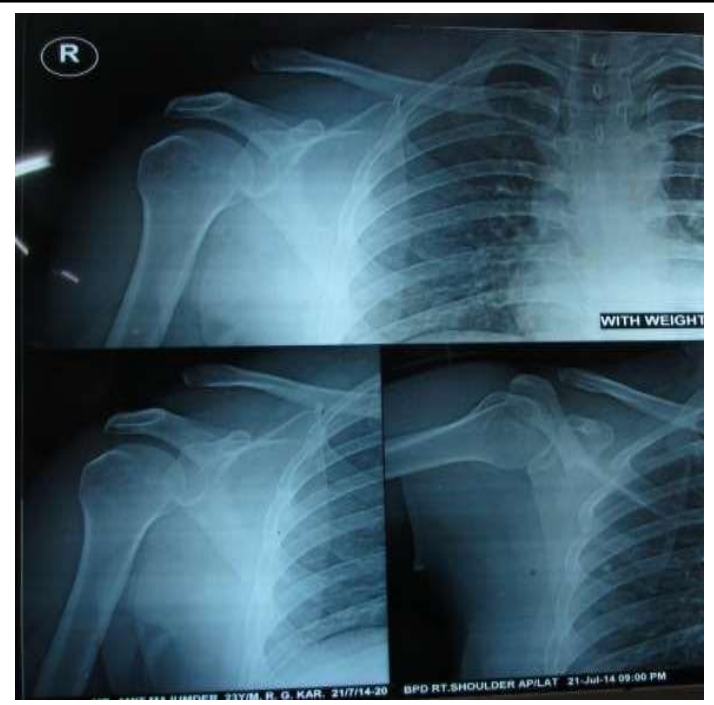

Radiological Photograph of a Case Having AC Joint Injury

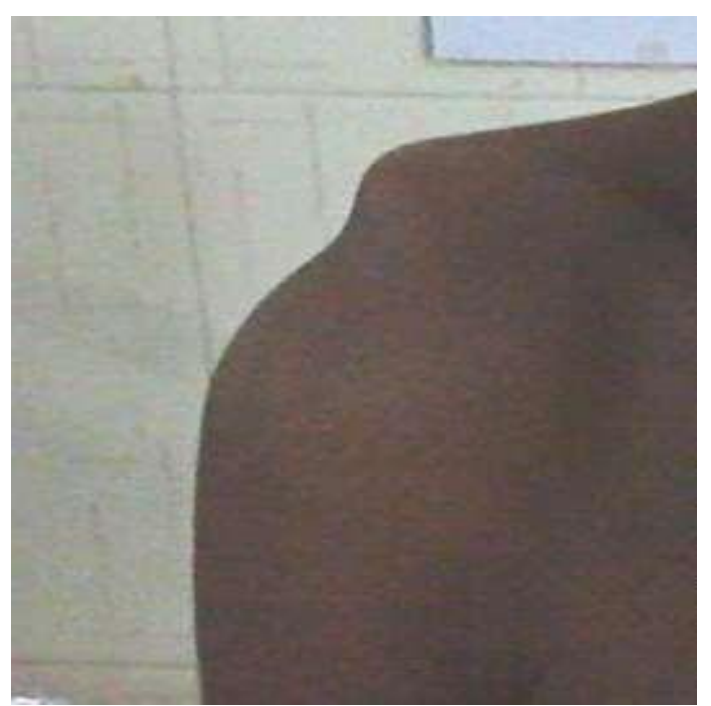

Clinical Photograph Showing Prominence of Lateral end of Clavicle Indicating AC Joint Dislocation

\section{Operative Procedure}

During surgery patient is positioned in a beach chair position. The approach to coracoclavicular joint performed through a sagittal skin incision which is 5 to $6 \mathrm{~cm}$ long on average and approximately $2 \mathrm{~cm}$ medial to acromioclavicular joint. After proper surgical exposure, the preparation of acromioclavicular joint and lateral clavicle is performed. If not already torn, the fascia joining the deltoid to the trapezius was divided at right angles to the skin incision. The clavicle was exposed subperiosteally at the level of the coracoid and the base of the coracoid was 
exposed between two small retractors. After careful removal of the soft tissues of the sub clavicular surface, the repositioning of the joint is performed by depressing the clavicle and elevating the arm by an assistant.

\section{Transfixation Screw Technique}

A guide wire for $4 \mathrm{~mm}$ CCS is passed from lateral end of clavicle to base of coracoid process under c-arm guidance maintaining reduction of AC joint. Then $3.2 \mathrm{~mm}$ cannulated drill bit is passed over guide wire and finally a $4 \mathrm{~mm}$ CCS with washer is applied over guide wire and after adequate compression by screw final reduction is checked. ${ }^{10}$
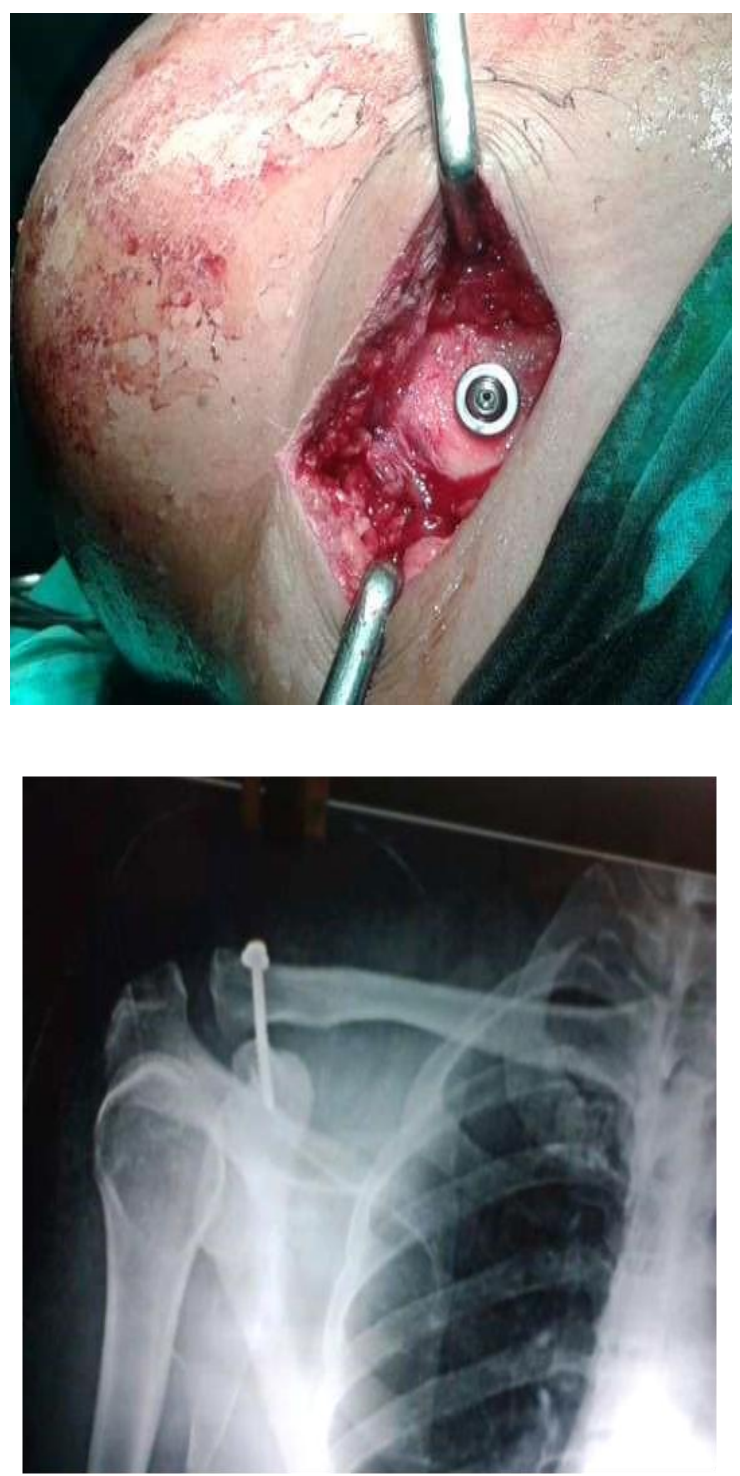

Intraoperative Image and Post Operative X-Ray of CCS with Washer in Transfixation Screw Technique

\section{Loop fixation by Mersilene tape and Endobutton}

Now, with a $2.8 \mathrm{~mm}$ drill bit 2 holes are made at distal end of clavicle approximately $15 \mathrm{~mm}$ apart, first drill hole being $30 \mathrm{~mm}$ away and second drill hole being $45 \mathrm{~mm}$ away from distal end of clavicle $^{13}$. A right angle forcep is used to hook the coracoid, and mersilene tape is passed beneath the coracoid with the help of right angle forceps. Now, mersilene tape was passed within the drill holes made on distal end of clavicle from inferior to superior surface and then two ends of mersilene tape was tied over endobutton after reducing ac joint dislocation in a figure of 8 manner.
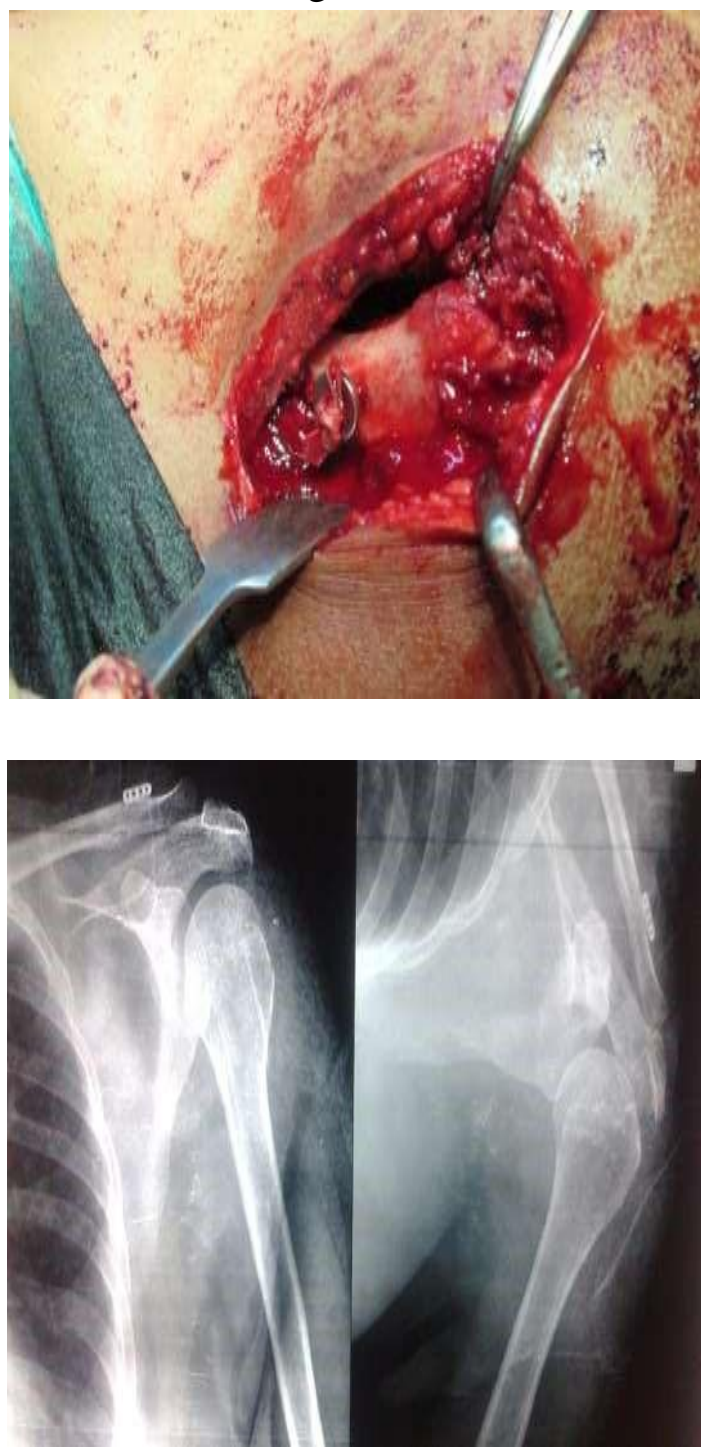

Intraoperaive Image and Post Operative X-Ray of Mersilene Tape with Endobutton in Loop Fixation Technique

Then torn ligaments were repaired. Deltotrapezius fascia repaired and wound closed in layer. 


\section{Post Operative Protocol}

Shoulder joint will be immobilized postoperatively in arm pouch for 3 weeks. Active ROM exercises done postoperatively in the recommended way. Suture removal done after 2 weeks.

Patients will be followed up at 4 weeks, 3 months \&12 months after surgery.

\section{Results \& Analysis}

The Transfixation group comprised of 12 patients and the Loop fixation group comprised of 12 patients. There were no intra-operative or postoperative complications apart from occasional pain, which was managed accordingly with analgesics. In one case of Transfixation group it was noticed AC joint dislocated due to cut out of screw. Revision surgery done by screw fixation and no further complication occurred.Follow up evaluation was done at intervals of 1 month (4 weeks), 6 months and 12 months. Distribution of patients according to age group are shown in Table1. Among 24 patients only 2 were female. All the patients were evaluated by DASH score and Constant Shoulder score both preoperativelyand post operatively and illustrated in Table2 \& 3. No patients.Average cost of implant in TS group was 700/- and average cost of implant in LF group was 3500/- $(\mathrm{p}<0.001$, significant, Fisher Exact Test). Mean operation time was 26.25 minutes and standard deviation was 3.19. In TS group, mean operation time was 23.00 minutes and standard deviation was 3.19. In LS group, mean operation time was 29.50 and standard deviation was 4.70. ( $\mathrm{p}=0.001$, significant, Student t test)

Table 1: Age distribution of patients studied

\begin{tabular}{|l|c|c|c|}
\hline \multirow{2}{*}{ Age in years } & \multicolumn{2}{|c|}{ MOIC } & \multirow{2}{*}{ Total } \\
\cline { 2 - 3 } & Group LF & Group TS & \\
\hline$<20$ & $0(0 \%)$ & $1(8.3 \%)$ & $1(4.2 \%)$ \\
\hline $20-30$ & $8(66.7 \%)$ & $5(41.7 \%)$ & $13(54.2 \%)$ \\
\hline $31-40$ & $1(8.3 \%)$ & $3(25 \%)$ & $4(16.7 \%)$ \\
\hline $41-50$ & $1(8.3 \%)$ & $2(16.7 \%)$ & $3(12.5 \%)$ \\
\hline $51-60$ & $2(16.7 \%)$ & $1(8.3 \%)$ & $3(12.5 \%)$ \\
\hline Total & $12(100 \%)$ & $12(100 \%)$ & $24(100 \%)$ \\
\hline Mean \pm SD & $33.33 \pm 12.14$ & $31.08 \pm 10.49$ & $32.21 \pm 11.15$ \\
\hline
\end{tabular}

Samples are age matched with $\mathrm{P}=0.632$
Table 2: DASH score in two groups of patients studied

\begin{tabular}{|l|c|c|c|c|}
\hline \multirow{2}{*}{ DASH } & \multicolumn{2}{|c|}{ MOIC } & \multirow{2}{*}{ Total } & \multirow{2}{*}{ P value } \\
\cline { 2 - 3 } & Group LF & Group TS & & \\
\hline Pre-op & $89.08 \pm 2.27$ & $90.08 \pm 2.54$ & $89.58 \pm 2.41$ & 0.321 \\
\hline Post op & $6.42 \pm 2.31$ & $6.42 \pm 3.45$ & $6.42 \pm 2.87$ & 1.000 \\
\hline Difference & 82.67 & 83.67 & 86.17 & - \\
\hline P value & $<0.001 * *$ & $<0.001 * *$ & $<0.001 * *$ & - \\
\hline
\end{tabular}
Between group: Student t test (Unpaired)
Within group: Student t test (Paired)

Table 3: Constant Shoulder score in two groups of patients studied

\begin{tabular}{|l|c|c|c|c|}
\hline \multirow{2}{*}{$\begin{array}{c}\text { Constant } \\
\text { Shoulder score }\end{array}$} & \multicolumn{2}{|c|}{ MOIC } & \multirow{2}{*}{ Total } & $\begin{array}{c}\text { P } \\
\text { value }\end{array}$ \\
\cline { 2 - 3 } & Group LF & Group TS & & 1.000 \\
\hline Pre-op & $59.67 \pm 3.52$ & $59.67 \pm 3.11$ & $59.67 \pm 3.25$ & 0.667 \\
\hline Post op & $90.92 \pm 3.70$ & $90.33 \pm 2.77$ & $90.63 \pm 3.21$ & - \\
\hline Difference & 31.25 & 30.67 & 30.95 & - \\
\hline P value & $<0.001 * *$ & $<0.001 * *$ & $<0.001 * *$ & - \\
\hline
\end{tabular}

Between group: Student t test (Unpaired)

Within group: Student t test (Paired)

\section{Discussion}

All of our patients reported satisfactory outcomes regardless of the procedure adopted. Younger age and patient with type III ac joint dislocation correlated with better outcome in both type of fixation, though the results of both the group of fixations are comparable. Patients with type V and VI acromioclavicular injuries had poorer outcome. Gender had no bearing on results. Both the procedures were found to be safe and reliable in producing the desired results. Loop fixation was slightly expensive than transfixation but results of both the group are comparable. Operating time was more in loop fixation group. Our study was limited in aspects like small sample size, short duration of follow up and variable patient characteristics. Keeping these in mind we conclude that both TF \& LF offer satisfactory outcome for acromioclavicular joint dislocation.

\section{Reference}

1. Adams FL. The Genuine Works of Hippocrates. Vol 1 and 2. New York, NY: William Wood; 1886. 
2. Beim GM. Acromioclavicular joint injuries. J Athl Train 2000; 35(3): 2617.

3. Flatow EL. The biomechanics of the acromioclavicular, sternoclavicular, and scapulothoracic joints. Instr Course Lect 1993; 42: 23745.

4. Shin SJ, Yun YH, Yoo JD. Coracoclavicular ligament reconstruction for acromioclavicular dislocation using 2 suture anchors and coracoacromial ligament transfer. Am J Sports Med 2009; 37(2): 34651.

5. Dias JJ, Gregg PJ. Acromioclavicular joint injuries in sport. Recommendations for treatment. Sports Med 1991; 11(2): 12532.

6. Rockwood CA Jr. Subluxations and dislocations about the shoulder. Injuries of the acromioclavicular joint. In: RockwoodCA Jr, Green DP, editors. Fractures in adults. Philadelphia, PA: JB Lippincott; 1984. p. 860-910.

7. Wirth MA, Rockwood CA Jr. Subluxations and dislocations about the glenohumeral joint. Rockwood CA, Bucholz R, HeckmanJD, Green DP, editors. Rockwood and Green's fractures in adults. 5th ed. Philadelphia: Lippincott Williams \& Wilkins; 2001. p. 673-91.

8. Press J, Zuckerman JD, Gallagher M, et al. Treatment of grade III acromioclavicular separations. Operative versus nonoperative management. Bull Hosp Jt Dis 1997;56:77-83.

9. Leidel BA, Braunstein V, Kirchhoff C, Pilotto S, Mutschler W, Biberthaler P. Consistency of long-term outcome of acute Rockwoodgrade III acromioclavicular joint separations after Kwiretransfixation. J Trauma 2009; 66(6): 1666-71.
10. Bosworth BM. Complete acromioclavicular dislocation. N Engl J Med 1949; 241(6): 2215.

11. Faraj AA, Ketzer B: The use of a hookplate in the management of acromioclavicular injuries: Report of ten cases. Acta Orthop Belg 2001;67:448-451.

12. Weaver JK Dunn HK: Treatment of acromioclavicular injuries especially complete acromioclavicular separation. J Bone Joint Surg 1972; 54: 1187- 94.

13. Mazzocca AD, Santangelo SA, Johnson ST, Rios CG, Dumonski ML, Arciero RA: A biomechanical evaluation of an anatomical coracoclavicular ligamentreconstruction. Am J Sports Med 2006; 34:236-246.

14. Bloom FA. Wire fixation in acromioclavicular dislocation. J Bone Joint Surg 1945; 27: 273-6.

15. Leidel BA, Braunstein V, Kirchhoff C, Pilotto S, Mutschler W, Biberthaler P. Consistency of long-term outcome of acute Rockwoodgrade III acromioclavicular joint separations after Kwiretransfixation. J Trauma 2009; 66(6): 1666-71.

16. Wolf EM, Pennington WT. Arthroscopic reconstruction for acromioclavicular joint dislocation. Arthroscopy 2001;17(5):558563.

17. Lafosse L, Baier GP, Leuzinger J: Arthroscopic treatment of acute and chronic acromioclavicular joint dislocation. Arthroscopy 2005;21:1017. 